\title{
End of Year, Editorial 2021
}

\author{
Murat Akova \\ Editor-in-Chief, Infectious Diseases and Clinical Microbiology \\ Department of Infectious Diseases and Clinical Microbiology, Hacettepe University School of Medicine, Ankara, Turkey
}

\section{Dear readers,}

With the current issue of the Journal, we will have left our 3rd year behind. So far, we have published 9 issues including highly interesting articles in infectious diseases and clinical microbiology.

IDCM is now being indexed by EBSCO, GALE and TUBITAK ULAKBIM TR INDEX. We have applied and are expecting positive reviews from others in the near future. When comparing the current performance of the Journal with that of 2020; the submissions have incredibly soared in 2021 (64\% increase) and almost 3-times more submissions were declined for publication than the previous year (our rejection rate was $22.9 \%$ so far). These figures are indicative that the Journal is leaving its infancy and proving itself as an emerging competitor in clinical infectious diseases and clinical microbiology segment.

This success could not have been possible without the authors and our reviewers' enthusiasm and tireless efforts.

We encourage all our readers and colleagues to submit their research results to IDCM for a speedy review, free of charge, and open access publication.

I wish you all a happy Holiday Season and a healthy, prosperous 2022.

With my very best regards.

Corresponding Author:

Murat Akova

E-mail:

makova@hacettepe.edu.tr

Published: December 30, 2021

Suggested citation:

Akova M. End of year, editorial 2021. Infect Dis Clin Microbiol 2021; 3: 109.

DOI: 10.36519/idcm.2021.113 